\title{
INTERFERÊNCIA DE PLANTAS DE COBERTURA SOBRE A INCIDÊNCIA DE PLANTAS INVASORAS E A PRODUÇÃO DE CEBOLA SOB SISTEMA DE PLANTIO DIRETO
}

\section{INTERFERENCE OF COVER CROPS ON THE WEED'S INCIDENCE AND ONION YIELD UNDER NO-TILLAGE}

\author{
Cintia de Camargo VILANOVA ${ }^{2}$ \\ Jucinei José COMIN ${ }^{3}$ \\ Claudinei KURTZ ${ }^{4}$ \\ Vilmar MÜLLER JÚNIOR ${ }^{5}$ \\ Julio Francisco URIARTE ${ }^{5}$ \\ Barbara Santos VENTURA ${ }^{5}$ \\ Monique SOUZA ${ }^{2}$ \\ Paulo Emilio LOVATO 6 \\ Eduardo LEGUIZAMON ${ }^{7}$ \\ Gustavo BRUNETTO ${ }^{8}$
}

\begin{abstract}
RESUMO
Mesmo com expectativas de expansão das áreas agrícolas brasileiras sob sistema de plantio direto (SPD), são poucos os trabalhos sobre o controle de plantas invasoras sem o uso de herbicidas, principalmente na produção de hortaliças, como a cebola. Para tanto, culturas utilizadas para cobertura do solo se mostram eficientes no controle do desenvolvimento de plantas invasoras através da inibição física e/ou alelopática. O objetivo do presente trabalho foi avaliar diferentes espécies de cobertura do solo, em sistemas em monocultivo ou consorciados, no controle de plantas invasoras e a sua interferência na produção de cebola sob SPD em transição agroecológica. O experimento foi instalado na Estação Experimental da Epagri em Ituporanga (SC), em um Cambissolo Húmico. Os tratamentos foram: T1: testemunha (vegetação invasora); T2: aveia preta (Avena strigosa); T3: centeio (Secale cereale); T4: nabo-forrageiro (Raphanus sativus); T5: consócio de nabo-forrageiro e centeio; T6: consórcio de nabo-forrageiro e aveia preta. Os tratamentos nabo-forrageiro e nabo-forrageiro + centeio aos 60 dias após a semeadura (DAS) e centeio e nabo-forrageiro + centeio aos 120 DAS propiciaram a maior produção de matéria seca de plantas de cobertura, enquanto a menor produção de matéria seca de plantas invasoras foi obtida nos tratamentos nabo-forrageiro + centeio, seguido de nabo-forrageiro no início do ciclo da cebola. A maior produção de bulbos de cebola da classe $3(50 \mathrm{~mm} \leq \phi<70 \mathrm{~mm})$ e total, em relação à testemunha, também foi obtida nestes dois tratamentos.

Palavras-chave: adubação verde, manejo ecológico do solo, Allium cepa.
\end{abstract}

Even with expectations of expanding Brazilian agricultural areas under no-tillage system, there are few studies that focus this system of yield without application of herbicide to weeds control are not very significant, mostly for vegetables production, like onions. In this sense, the use of cover crops presents efficient in weeds development control to inhibit by a physical barrier and/or its allelopathic effects. This study aimed to evaluate cover crops influences in the weeds control and onions yield under agroecological transition no-tillage system. The experimental area is located in Experimental Station of Epagri, Ituporanga (SC), in a Humic Haplumbrept soil. Treatments were: T1: control - weed community; T2: oat (Avena strigosa); T3: rye (Secale cereale); T4: white radish (Raphanus sativus); T5: white radish intercropped with rye; T6: white radish intercropped with oat. The treatments Raphanus sativus + Secale cereale at 60 days after sowing and Raphanus sativus + Secale cereale at 120 days after sowing propitiated highest dry matter yield of cover crops, while the lowest dry matter yield of weeds was obtained in treatments Raphanus sativus + Secale cereale, followed by Raphanus sativus in the early season onion. The highest yield of onion bulbs of the class $3(50 \mathrm{~mm} \leq \phi<70 \mathrm{~mm})$ and total, compared to the control, was also obtained in these two treatments.

Key-words: green manure, soil ecological management, Allium cepa.

\footnotetext{
${ }^{1}$ Trabalho desenvolvido com recursos do MDA/SAF/CNPq - Edital n.58/2010 e Fundação de Amparo à Pesquisa e Inovação do Estado de Santa Catarina (FAPESC), Edital Ciências Agrárias - FAPESC - 08/2009.

${ }^{2}$ Bolsista do Conselho Nacional de Desenvolvimento Científico e Tecnológico (CNPq) e Coordenação de Aperfeiçoamento de Pessoal de Nível Superior (CAPES), Mestranda do Programa de Pós-Graduação em Agroecossistemas, Centro de Ciências Agrárias, Universidade Federal de Santa Catarina, Florianópolis, SC, Brasil. Email: cintiavilanova@hotmail.com.

${ }^{3}$ Professor Associado do Departamento de Engenharia Rural e do Programa de Pós-Graduação em Agroecossistemas, Centro de Ciências Agrárias, Universidade Federal de Santa Catarina, Rod. Admar Gonzaga, 1346, CP: 476, 88040-900, Florianópolis, SC, Brasil. Email: jcomin@cca.ufsc.br. Autor para correspondência.

${ }^{4}$ Pesquisador da Empresa de Pesquisa Agropecuária e Extensão de Rural de Santa Catarina (EPAGRI), Estação Experimental de Ituporanga, Ituporanga, SC, Brasil. Email: kurtz@epagri.sc.gov.br.

${ }^{5}$ Estudante de graduação em Agronomia, Centro de Ciências Agrárias, Universidade Federal de Santa Catarina, Florianópolis, SC, Brasil.

${ }^{6}$ Professor Associado do Departamento de Engenharia Rural e do Programa de Pós-Graduação em Agroecossistemas, Centro de Ciências Agrárias, Universidade Federal de Santa Catarina, Rod. Admar Gonzaga, 1346, CP: 476, 88040-900, Florianópolis, SC, Brasil. Email: paulo.lovato@ufsc.br.

paulo.lovato@ufsc.br.

${ }^{8}$ Professor Adjunto do Departamento de Solos e do Programa de Pós-Graduação em Ciência do Solo, Centro de Ciências Rurais, Universidade Federal de Santa Maria, SC. Email: brunetto.gustavo@gmail.com.
} 
VILANOVA, C.C. et al. Interferência de planta de cobertura...

\section{INTRODUÇÃO}

A cebolicultura constitui-se em atividade socioeconômica relevante para São Paulo (SP), Santa Catarina (SC) e Rio Grande do Sul (RS), concentrando cerca de $77 \%$ da produção nacional. Em SC, mais de 18 mil famílias de agricultores a tem como principal atividade, concentrando produção nas microrregiões de Ituporanga e Rio do Sul (Epagri, 2000). Com expectativa de expansão, o Brasil apresenta cerca de 25 milhões de hectares sob sistema de plantio direto (SPD), exigindo cuidados para garantir seus benefícios, como diminuição de perdas de solo, ciclagem de nutrientes e manejo de plantas invasoras (Gomes Jr \& Christofolet, 2008).

Um grande desafio para a implantação do SPD é a eliminação de herbicidas e o controle eficiente de plantas invasoras, com altas produtividades das culturas econômicas e conservação das características edáficas (Darolt \& Skora Neto, 2002; Altieri et al., 2011). No SPD de hortaliças, como a cebola, o princípio da prevenção deve ser privilegiado, evitando a ressemeadura das invasoras, e ainda assim, podem ser necessárias capinas.

A produção distinta de matéria seca (MS) das culturas de cobertura pode evitar a germinação e a emergência das plantas invasoras, seja pela liberação de compostos alelopáticos e/ou pela formação de barreira física (Gomes Jr \& Christofoleti, 2008, Altieri et al., 2011). Assim, o uso de culturas de cobertura em SPD que produzam adequadas quantidades de MS pode reduzir os custos do manejo das plantas invasoras e prevenir a produção de sementes dessas espécies durante o ciclo de cobertura, evitando o seu crescimento durante o ciclo das culturas de interesse econômico (Brennan \& Smith, 2005). O trabalho objetivou avaliar diferentes espécies de plantas de cobertura do solo sobre o controle de plantas invasoras e o sua interferência sobre a produção de cebola sob SPD em transição agroecológica.

\section{MATERIAL E MÉTODOS}

O experimento foi instalado na Estação Experimental de Ituporanga (EEIT), vinculada à Empresa de Pesquisa Agropecuária e Extensão Rural de Santa Catarina (EPAGRI), Ituporanga (SC) $\left(27^{\circ}\right.$ 28'34"S; 49³4'26'W e 390m de altitude). O clima da região é do tipo Subtropical Mesotérmico Úmido (Cfa) (classificação de Köppen) com verões quentes, chuvas distribuídas durante todo o ano e temperatura média anual de $17^{\circ} \mathrm{C}$. O solo foi classificado como Cambissolo Húmico com textura média e, na camada de $0-20 \mathrm{~cm}$, antes da instalação do experimento apresentava: $380 \mathrm{~g} \mathrm{~kg}^{-1}$ de argila, $40 \mathrm{~g} \mathrm{~kg}$ ${ }^{-1}$ de matéria orgânica, $\mathrm{pH}$ em água 6,2 ; İ́ndice SMP 6,2 ; fósforo $(P)$ disponível $26,6 \mathrm{mg} \mathrm{dm}^{-3}$ e potássio (K) trocável $145,2 \mathrm{mg} \mathrm{dm}^{-3}$ (extraídos por Mehlich 1); alumínio (Al) trocável $0,0 \mathrm{cmol}_{\mathrm{C}} \mathrm{kg}^{-1}$, cálcio $(\mathrm{Ca})$ trocável 7,2 $\mathrm{cmol}_{\mathrm{c}} \mathrm{kg}^{-1}$ e magnésio $(\mathrm{Mg})$ trocável 3,4 $\mathrm{cmol}_{\mathrm{c}} \mathrm{kg}^{-1}$ (extraídos por KCl $1 \mathrm{~mol} \mathrm{~L}^{-1}$ ); Capacidade de Troca de Cátions (CTC) $14,32 \mathrm{cmol}_{\mathrm{c}} \mathrm{kg}^{-1}$, satura- ção da $\mathrm{CTC}_{\mathrm{pH7}, 0}$ por bases (V) 7,6\% e saturação da $\mathrm{CTC}_{\text {efetiva }}$ por $\mathrm{Al} 3,4 \%$.

O experimento foi instalado em uma área com histórico de cultivo convencional durante 30 anos. Em 1995, foi aplicado calcário na superfície do solo, com posterior incorporação, para elevar o pH em água até 6,0 . No mesmo ano, foi adotado o SPD com rotação de culturas e o cultivo de plantas de cobertura. Em 2009, no momento da instalação do experimento, a vegetação espontânea foi dessecada, usando o herbicida glifosato. A partir de então, não foram mais utilizadas aplicações de agrotóxicos e fertilizantes minerais. Os tratamentos implantados foram: testemunha, com vegetação de plantas invasoras (T1); aveia preta (Avena strigosa) com $120 \mathrm{~kg}$ $\mathrm{ha}^{-1}$ de sementes (T2); centeio (Secale cereale) com $120 \mathrm{~kg} \mathrm{ha}^{-1}$ de sementes (T3); nabo-forrageiro (Raphanus sativus) com $20 \mathrm{~kg} \mathrm{ha}^{-1}$ de sementes (T4); nabo-forrageiro com $10 \mathrm{~kg} \mathrm{ha}^{-1}$ de sementes + centeio com $60 \mathrm{~kg} \mathrm{ha}^{-1}$ de sementes (T5); naboforrageiro com $10 \mathrm{~kg} \mathrm{ha}^{-1}$ de sementes + aveia preta com $60 \mathrm{~kg} \mathrm{ha}^{-1}$ de sementes (T6). O delineamento experimental foi de blocos ao acaso com oito repetições, sendo que cada unidade experimental (parcela) possuía $25 \mathrm{~m}^{2}(5 \times 5 \mathrm{~m})$.

A amostragem de espécies de cobertura do solo foi realizada aos 60 dias após a semeadura (DAS) e aos 120 DAS, com a utilização de um quadrado de $0,50 \times 0,50 \mathrm{~m}$, lançado aleatoriamente três vezes em cada parcela, totalizando uma área amostrada de $0,75 \mathrm{~m}^{2}$ por parcela. Em cada quadrado foram coletadas as plantas de cobertura, para a posterior determinação da matéria seca das espécies. A amostragem das plantas invasoras foi realizada aos 30 dias após o plantio (DAP) e aos 85 DAP, com a utilização da mesma metodologia utilizada para a amostragem das espécies de cobertura, ou seja, coletando-se as plantas invasoras. Logo depois de cada coleta, a biomassa das plantas foi submetida à secagem em estufa com circulação de ar forçado e com temperatura de $65^{\circ} \mathrm{C}$ até o peso constante e, em seguida foi determinada a matéria seca.

Em agosto de 2009 as plantas de cobertura foram acamadas utilizando-se um rolo faca. Em seguida, foram aplicados na área $96 \mathrm{~kg}$ de $\mathrm{P}_{2} \mathrm{O}_{5}$ ha 1 , na forma de fosfato natural de Gafsa, e $175 \mathrm{~kg}$ de $\mathrm{P}_{2} \mathrm{O}_{5} \mathrm{ha}^{-1}, 125 \mathrm{~kg}$ de $\mathrm{K}_{2} \mathrm{O} \mathrm{ha}^{-1}, 160 \mathrm{~kg}$ de $\mathrm{N} \mathrm{ha}^{-1}$, na forma de dejetos de aves, metade aplicada no plantio das mudas e o restante 30 dias após o plantio (DAT). Posteriormente, foram abertos sulcos usando uma máquina de plantio direto e foram transplantadas manualmente as mudas de cebola, cv. 'Empasc 352' - Bola Precoce, com espaçamento de $0,40 \mathrm{~m}$ entre linhas e $0,10 \mathrm{~m}$ entre mudas (250.000 plantas $\mathrm{ha}^{-1}$ ). Foram realizadas duas capinas ao longo do ciclo da cebola, a primeira aos 50 DAT e a segunda aos 80 DAT.

Em novembro de 2009 foi realizada a colheita manual da cebola em oito linhas centrais de cada parcela e os bulbos permaneceram na superfície do 
VILANOVA, C.C. et al. Interferência de planta de cobertura...

solo por 14 dias para a secagem e perda de água das folhas. Posteriormente, os bulbos foram classificados pelo diâmetro transversal nas classes 2 $(35 \mathrm{~mm} \leq \phi<50 \mathrm{~mm})$ e $3(50 \mathrm{~mm} \leq \phi<70 \mathrm{~mm})$ conforme portaria $n^{\circ} 529$ 18/08/1995 (Brasil, 1995) e, em seguida, foram pesados.

Os dados de produção de matéria seca das plantas de cobertura e de espécies invasoras foram submetidos ao teste Fmax para verificação de homogeneidade no conjunto de dados. Uma vez observada a ausência de normalidade, foi usado o teste de Kruskal-wallis para se verificar diferenças entre os tratamentos com nível de significância $1 \%$. Quando se verificou diferenças, aplicou-se o teste de Dunn com base na ordenação (ranks) dos dados e não em seus valores intrínsecos, pois o procedimento distribui o conjunto de dados em um ranque de acordo com a diferença na somatória de posições. Os resultados da produção da cebola foram submetidos à ANOVA e quando os efeitos foram significativos as médias foram comparadas pelo Teste Tukey $(\alpha=1 \%)$.

\section{RESULTADOS E DISCUSSÃO} ras

Matéria seca de plantas de cobertura e invaso-

A produção de matéria seca da parte aérea das culturas de cobertura, aos 60 dias após a semeadura (DAS), nos tratamentos nabo-forrageiro (T4) e nabo-forrageiro + centeio (T5) foi superior àquela encontrada nos tratamentos nabo-forrageiro + aveia preta (T6) e aveia preta (T2). Estes por sua vez apresentaram maior produção que o tratamento centeio (T3), que diferiu da testemunha (T1) (Tabela 1). Já na avaliação aos 120 DAS a produção de matéria seca foi superior no tratamento T3, que diferiu de T5. Em seguida, as maiores produções de matéria seca de plantas de cobertura ocorreram nos tratamentos T2 e T4, com valores superiores a T6, sendo este superior à testemunha. A maior produção de matéria seca dos tratamentos naboforrageiro e nabo-forrageiro + centeio aos 60 DAS e de centeio, seguido de nabo-forrageiro + centeio, aos 120 DAS, pode ser consequência do sistema radicular profundo do centeio, possibilitando a exploração de um maior volume de solo, o que potencializa maior absorção de água e nutrientes; à sua rusticidade e elevada capacidade de perfilhamento. No caso dos tratamentos com nabo-forrageiro, o resultado pode ser consequência do rápido crescimento inicial e da elevada ramificação da parte aérea. Na safra de 2010, Vilanova (2011) verificou, no presente experimento, que as maiores produções de matéria seca das plantas de cobertura ao final do ciclo ocorreram nos tratamentos nabo-forrageiro + cevada $\left(4,6 \mathrm{t} \mathrm{ha}^{-1}\right)$, nabo-forrageiro + centeio $(4,3$ $\left.\mathrm{t} \mathrm{ha}^{-1}\right)$, nabo-forrageiro $\left(4,2 \mathrm{t} \mathrm{ha}^{-1}\right)$ e centeio $(3,0 \mathrm{t}$ ha $\left.{ }^{-1}\right)$. Já Souza et al. (2013) verificaram na safra 2011 que os tratamentos com monocultivo de centeio e de nabo-forrageiro apresentaram a maior produção de matéria seca da parte aérea aos 60 e 95 DAS, enquanto aos 80 DAS a maior produção ocorreu no tratamento nabo-forrageiro e nos tratamentos consorciados, nabo-forrageiro + centeio e naboforrageiro + aveia preta.

Tabela 1. Produção de matéria seca das culturas de cobertura e das plantas invasoras.

\begin{tabular}{|c|c|c|c|c|c|c|c|c|}
\hline \multirow[b]{3}{*}{ Tratamentos } & \multicolumn{4}{|c|}{ Culturas de cobertura } & \multicolumn{4}{|c|}{ Plantas invasoras } \\
\hline & \multicolumn{2}{|c|}{60 DAS } & \multicolumn{2}{|c|}{120 DAS } & \multicolumn{2}{|c|}{30 DAP } & \multicolumn{2}{|c|}{85 DAP } \\
\hline & $\begin{array}{l}\text { Médias } \\
\text { t ha }^{-1}\end{array}$ & $\begin{array}{c}\text { Soma } \\
\text { dos pos- } \\
\text { tos }\end{array}$ & $\begin{array}{l}\text { Médias } \\
\text { t ha }^{-1}\end{array}$ & $\begin{array}{c}\text { Soma } \\
\text { dos pos- } \\
\text { tos }\end{array}$ & $\begin{array}{c}\text { Médias } \\
\text { t ha }^{-1}\end{array}$ & $\begin{array}{c}\text { Soma } \\
\text { dos } \\
\text { postos }\end{array}$ & $\begin{array}{l}\text { Médias } \\
\text { t ha }^{-1}\end{array}$ & $\begin{array}{c}\text { Soma } \\
\text { dos pos- } \\
\text { tos }\end{array}$ \\
\hline $\mathrm{T} 1$ & $0,05 d$ & 37,0 & $0,98 e$ & 38,0 & $0,69 a$ & 305,5 & $1,28 a$ & 141,5 \\
\hline T2 & $0,57 b$ & 214,5 & $4,92 b c$ & 231,0 & $0,88 b$ & 284,5 & $1,34 a$ & 152,5 \\
\hline T3 & $0,47 c$ & 175,5 & $4,96 a$ & 261,5 & $0,26 d$ & 154,0 & $1,40 a$ & 164,5 \\
\hline $\mathrm{T} 4$ & $0,73 a$ & 267,0 & $4,64 c$ & 218,0 & $0,22 e$ & 122,5 & $1,03 a$ & 131,0 \\
\hline T5 & $0,73 a$ & 255,0 & $4,90 \mathrm{~b}$ & 239,0 & $0,16 f$ & 105,0 & $1,07 a$ & 130,5 \\
\hline T6 & $0,64 b$ & 227,0 & $4,73 d$ & 188,5 & $0,52 c$ & 204,5 & $1,30 a$ & 141,0 \\
\hline DMS & & 14,4 & & 14,9 & & 14,4 & & - \\
\hline
\end{tabular}

T1: testemunha*; T2: aveia preta; T3: centeio; T4: nabo-forrageiro; T5: consócio de nabo-forrageiro e centeio; T6: consórcio de nabo-forrageiro e aveia preta; DAS = dias após a semeadura; DAP = dias após o plantio da cebola; médias na coluna seguidas pela mesma letra não diferem entre si pelo teste de Dunn $(\alpha=1)$; DMS: diferença mínima significativa. 
VILANOVA, C.C. et al. Interferência de planta de cobertura...

A menor produção de matéria seca das plantas invasoras aos 30 DAP ocorreu no tratamento T5, seguido de $\mathrm{T} 4$, com a segunda menor produção, e em terceiro o T3, que diferiu de T6. A quinta menor produção de matéria seca de plantas invasoras ocorreu no T2, que diferiu da testemunha (Tabela 1) A menor produção de matéria seca das plantas invasoras nos tratamentos T5 e, em seguida, T4 pode ser atribuída ao intenso abafamento causado pela formação de barreira física da palhada produzida pelas plantas de cobertura, a qual diminui a incidência luminosa e impede a germinação das sementes e o desenvolvimento das plântulas (Gomes Jr \& Christofoleti, 2008), como pelo efeito alelopático das plantas de cobertura. Os compostos glucosinolatos contidos em brássicas, como o naboforrageiro, contribuem para manejo de plantas invasoras, reduzindo a sua densidade e biomassa (Wu et al., 1999; Uremis et al., 2009), enquanto o centeio pode suprimir plantas invasoras em condições de campo através de compostos como ácido Bfenilático e ácido B-hidroxiburítico (Shilling et al., 1986; Barnes \& Putnam 1987).

Produção de cebola e classificação de bulbos

A maior produção de bulbos de cebola da classe 3 e a produção total foram maiores nos tratamentos T3, T4, T5 e T6, mas somente T4 e T5 diferiram da testemunha (Tabela 2). A maior produção de cebola nos tratamentos com nabo-forrageiro em monocultivo e consorciado com o centeio, o que pode ser consequência da maior quantidade de $\mathrm{N}$ e $\mathrm{P}$ acumulada na parte aérea do nabo-forrageiro e à sua rápida liberação, quando da decomposição dos resíduos na superfície do solo (Crusciol et al., 2005; Heinz et al., 2011), o que contribuiu para a nutrição da cebola. Na safra de 2010, a produção de bulbos no presente experimento, determinada por Souza et al. (2013), não apresentou diferenças entre os tratamentos nas classes 4 e 2, enquanto a maior produção de bulbos da classe 3 e total ocorreu nos tratamentos com espécies de plantas de cobertura (produção média respectivamente de $5,4 \mathrm{t} \mathrm{ha}^{-1}$ e 13 $\left.\mathrm{t} \mathrm{ha}^{-1}\right)$. A produção de bulbos da classe 3 e total no tratamento testemunha foi $61 \%$ e $27 \%$ menor, respectivamente, que aquela dos tratamentos com plantas de cobertura.

A observação dos dados de produção de matéria seca das plantas de cobertura, onde todos os tratamentos diferiram da testemunha nas duas datas avaliadas (Tabela 1), indica que os resíduos das plantas de cobertura em decomposição na superfície do solo liberaram nutrientes (Pacheco et al., 2011a, b) durante o ciclo da cebola, que foram, em parte, absorvidos pelas plantas. Os resíduos das plantas de cobertura também protegem a superfície do solo contra o impacto das gotas da chuva, diminuindo as perdas de solo por erosão hídrica (Oliveira et al., 2012) e o selamento superficial, o que resulta em condições mais favoráveis à infiltração de água no solo (Gonçalves \& Moraes, 2012). Altieri et al. (2011) também sugerem que o uso de plantas de cobertura pode melhorar a supressão de plantas invasoras e, consequentemente, o rendimento das culturas agrícolas por meio de interferência física, alelopatia e também pelo melhoria da qualidade do solo.

Os tratamentos T4 e T5, além de apresentarem a maior produção de bulbos de cebola da classe 3 e produção total (Tabela 2), também apresentaram, em segundo e primeiro lugar, a menor produção de matéria seca de plantas invasoras, aos 60 DAS (Tabela 1). Nestes tratamentos, a menor quantidade de plantas invasoras contribuiu para o desenvolvimento da cultura, pois estas plantas, em razão de diferentes épocas de emergência e de sua competição extremamente eficiente com as culturas agrícolas, interferem negativamente no rendimento das plantas cultivadas (Soares et al., 2004; Barroso et al., 2012). A convivência de plantas de cebola com plantas invasoras durante todo o ciclo da cultura reduziu a produção da hortaliça em $94,5 \%$ (Soares et al., 2004).

Em relação à produção de bulbos da classe 2 , não houve diferença significativa entre os tratamentos (Tabela 2). Contrariamente à testemunha, todos os demais tratamentos apresentaram apodrecimento de bulbos. O tratamento T4 apresentou ocorrência de bulbos apodrecidos superior aos tratamentos T1, T2, T3, porem, não diferiu dos tratamentos T5 e T6.

\section{CONCLUSÕES}

O cultivo de nabo-forrageiro e nabo-forrageiro + centeio aos 60 dias após a semeadura e de centeio e nabo-forrageiro + centeio aos 120 dias após a semeadura, propiciaram a maior produção de matéria seca de plantas de cobertura. A menor produção de matéria seca de plantas invasoras foi obtida nos tratamentos nabo-forrageiro + centeio, seguido de nabo-forrageiro no início do ciclo da cebola. A maior produção de bulbos de cebola da classe 3 e total em relação à testemunha também foi obtida nestes dois tratamentos. 
VILANOVA, C.C. et al. Interferência de planta de cobertura...

Tabela 2. Produção de bulbos e produção total da cebola.

\begin{tabular}{lcccc} 
& \multicolumn{4}{c}{ Produção de cebola } \\
\cline { 2 - 5 } & Classe 3 & Classe 2 & Podres & Total \\
\hline Tratamentos & \multicolumn{4}{c}{ t ha $^{-1}$} \\
\hline T1 & $1,08 \mathrm{c}$ & $9,33 \mathrm{a}$ & $0,0 \mathrm{~b}$ & $10,41 \mathrm{c}$ \\
T2 & $1,40 \mathrm{bc}$ & $9,47 \mathrm{a}$ & $0,04 \mathrm{~b}$ & $10,91 \mathrm{bc}$ \\
T3 & $2,19 \mathrm{abc}$ & $10,21 \mathrm{a}$ & $0,07 \mathrm{~b}$ & $12,47 \mathrm{abc}$ \\
T4 & $3,64 \mathrm{a}$ & $9,56 \mathrm{a}$ & $0,33 \mathrm{a}$ & $13,53 \mathrm{a}$ \\
T5 & $2,77 \mathrm{ab}$ & $9,94 \mathrm{a}$ & $0,17 \mathrm{ab}$ & $12,88 \mathrm{ab}$ \\
T6 & $2,33 \mathrm{abc}$ & $9,34 \mathrm{a}$ & $0,15 \mathrm{ab}$ & $11,82 \mathrm{abc}$ \\
CV & 48,8 & 8,9 & 130,0 & 13,0 \\
\hline
\end{tabular}

T1: testemunha; T2: aveia preta; T3: centeio; T4: nabo-forrageiro; T5: consócio de nabo-forrageiro e centeio; T6: consórcio de nabo-forrageiro e aveia preta; médias na coluna seguidas pela mesma letra não diferem entre si pelo teste de Tukey $(\alpha=1) ; C V$ : coeficiente de variação (\%).

\section{REFERÊNCIAS}

1. AltiERI, M.A.; LANA, M.A.; BITTENCOURT, H.V.; KIELING, A.; COMIN, J.J.; LOVATO, P.E. Enhancing crop productivity via weed suppression in organic no-till cropping systems in Santa Catarina, Brazil. Journal of Sustainable Agriculture, v. 35, n. 8, p. 855-869, 2011.

2. BARNES, J.P., PUTNAM, A.R. Role of benzoxazinones in allelopathy of rye. Journal of Chemical Ecology, v. 13, n. 4, p. 889-906, 1987.

3. BRASIL. Ministério da Agricultura, Abastecimento e Reforma Agrária. Portaria n. 529 de 18 de agosto de 1995. Diário Oficial da República Federativa do Brasil, Brasília, Seção 1, p.13513. Set. 1995.

4. BRENNAN, E.B.; SMITH, R.F. Winter cover crop growth and weed suppression on the central coast of California. Weed Technology, v.19, n.4, p. 1017-1024, 2005.

5. CRUSCIOL, C.A.C.; COTTICA, R.L.; LIMA, E.V.; ANDREOTTI, M.; MORO, E.; MARCON, E. Persistência de palhada e liberação de nutrientes do nabo forrageiro no plantio direto. Pesquisa Agropeuária Brasileira, v. 40, n. 2, p.161-168, 2005.

6. DAROLT, M.R.; SKORA NETO, F. Sistema de plantio direto em agricultura orgânica. Revista Plantio Direto. n. 70, jul/ago. Passo Fundo: Aldeia Norte Editora: p. 28-30, 2002.

7. EPAGRI. Sistema de produção para cebola: Santa Catarina. Florianópolis, 2000. 91p. (Epagri. Sistemas de Produção, 16)

8. GOMES JR, F.G.; CHRISTOFOLETI, P.J. Biologia e manejo de plantas daninhas em áreas de plantio direto. Planta daninha, v. 26, n. 4, p.789-798, 2008.

9. GONÇALVES, F.C.; MORAES, M.H. Porosidade e infiltração de água do solo sob diferentes sistemas de manejo. Irriga, v. 17, n. 3, p. 337-345, 2012.

10. HEINZ, F. GARBIATE, M.G.; VIEGAS NETO, A.L.; MOTA, L.H.S.; CORREIA, A.M.P.; VITORINO, A.C.T. Decomposição e liberação de nutrientes de resíduos culturais de crambe e nabo forrageiro. Ciência Rural, v. 41, n. 9, p.1549-1555, 2010.

11. OLIVEIRA; J.G.R.; RALISCH, R.; GUIMARÃES, M.F.; BARBOSA, G.M.C.; TAVARES FILHO, J. Erosão no plantio direto: perda de solo, água e nutrients. Boletim de Geografia, v. 30, n. 3, p. 91-98, 2012.

12. PACHECO, L.P.; BARBOSA, J.M.; LEANDRO, W.M.; MACHADO, P.L.O.A.; ASSIS, R.L.; MADARI, B.E.; PETTER, F.A. Produção e ciclagem de nutrientes por plantas de cobertura nas culturas de arroz de terras altas e de soja. Revista Brasileira de Ciência do Solo, v. 35, n. 5, p.1787-1799, $2011 \mathrm{a}$.

13. PACHECO, L.P.; LEANDRO, W.M.; MACHADO, P.L.O.A.; ASSIS, R.L.; COBUCCI, T.; MADARI, B.E.; PETTER, F.A. Produção de fitomassa e acúmulo e liberação de nutrientes por plantas de cobertura na safrinha. Pesquisa Agropecu]aria Brasileira, v.46, n.1, p.17-25, $2011 \mathrm{~b}$.

14. SHILLING, D.G.; JONES, L.A.; WORSHAM, A.D.; PARKER, C.E.; WILSON, R.F. Isolation and Identification of Some Phytotoxic Compounds from Aqueous Extracts of Rye (Secale cereale L.). Journal of Agricultural and Food Chemistry. v. 34, n. 4, p. 633-638, 1986.

15. SOARES, D.J.; GRAVENA, R.; PITELLI, R.A. Efeito de diferentes períodos de controle das plantas daninhas na produtividade da cultura da cebola. Planta Daninha, v. 22, n. 4, p. 517-527, 2004.

16. SOUZA, M.; COMIN, J.J.; LEGUIZAMÓN, E.S.; KURTZ, C.; BRUNETTO, G.; MÜLLER JÚNIOR, V.; 
VILANOVA, C.C. et al. Interferência de planta de cobertura...

VENTURA, B.; CAMARGO, A.P. Matéria seca de plantas de cobertura, produção de cebola e atributos químicos do solo em sistema plantio direto agroecológico. Ciência Rural, v. 43, n. 1, p. 21-27, 2013.

17. UREMIS, I.; ARSLAN, M.; ULUDAG, A. SANGUN, M.K. Allelopathic potentials of residues of 6 brassica species on johnsongrass [Sorghum halepense (L.) Pers.] African Journal of Biotechnology, v. 8, n.15, p. 3497-3501, 2009.

18. VILANOVA, C. C. Sistema de plantio direto de cebola: contribuições das plantas de cobertura no manejo ecológico de plantas espontâneas. 2011. 76 p. Dissertação (Mestrado em Agroecossistemas). Centro e Ciências Agrárias, Universidade Federal de Santa Catarina, Florianópolis, 2011.

19. WU, H.; PRATLEY, J.; LEMERLE, D.; HAIG, T. Crop cultivars with allelopathic capability. Weed Research, v. 39, n.3, p.171-180, 1999.

Recebido em 26/08/2011

Aceito em 05/06/2013 